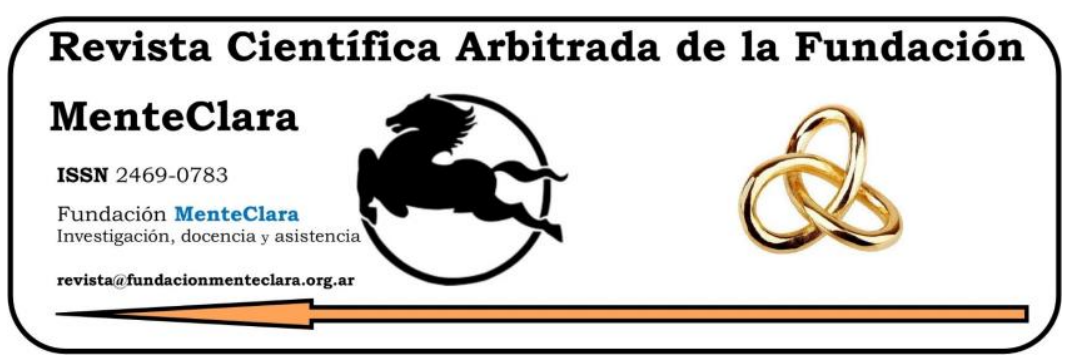

Artículos atravesados por (o cuestionando) la idea del sujeto -y su género- como una construcción psicobiológica de la cultura. Articles driven by (or questioning) the idea of the subject -and their gender- as a cultural psychobiological construction.

Vol. 6 (2021), enero-diciembre

ISSN 2469-0783

https://datahub.io/dataset/2021-6-e217

\title{
REFLEXIONES SOBRE LA OTRA CARA DE LA PANDEMIA EN LOS ANDES DEL PERÚ
}

REFLECTIONS ON THE OTHER SIDE OF THE PANDEMIC IN THE ANDES OF PERU

Ricardo Arango Olarte ${ }^{1}$, Aparicio Chanca Flores ${ }^{2}$, Antonio Nahuincopa Arango ${ }^{3}$

Cómo citar este artículo / Citation: Arango Olarte R., Chanca Flores A. \& Ñahuincopa Arango A. (2021). Reflexiones sobre la otra cara de la pandemia en los Andes del Perú.

Revista Cientifica Arbitrada de la Fundación MenteClara, Vol. 6 (217). DOI:

https://doi.org/10.32351/rca.v6.217

Copyright: (C) 2021 RCAFMC. Este artículo de acceso abierto es distribuido bajo los términos de la licencia Creative Commons Attribution 4.0 International License (CC BY 4.0). Recibido: 03/02/2021. Aceptado: 05/02/2021 Publicación online: 06/02/2021

Conflicto de intereses: Ninguno que declarar.

\section{Resumen}

En este trabajo de investigación, intentamos vislumbrar el poder de la inteligencia del hombre como solucionador de problemas en la coyuntura de la pandemia, originada por la COVID-19. Fruto de ello, presentamos algunos aspectos positivos de esta crisis sanitaria: la reflexión y la reinvención de actividades humanas; las bondades de la educación virtual; el fortalecimiento de la unidad familiar; el valor de la vida y dignidad; y, el cuidado de la naturaleza. Son temas de reflexión relevantes que nos ayuda a ver la vida desde una perspectiva de actitud mental positiva y una invitación a reorganizar nuestro proyecto vital postpandemia.

\footnotetext{
${ }_{1}^{1}$ Universidad Nacional del Centro del Perú, Facultad de Antropología, Perú.

ricardoarango9@gmail.com

2 Universidad Nacional del Centro del Perú, Facultad de Antropología, Perú. achanca@uncp.edu.pe

3 Universidad de Navarra, España. antonio3560@gmail.com
} 


\begin{abstract}
In this research work we try to glimpse the power of man's intelligence as a problem solver in the conjuncture of the pandemic, caused by COVID-19. As a result, we present some positive aspects of this health crisis: reflection and reinvention of human activities; the benefits of virtual education; the strengthening of the family unit; the value of life and dignity; and, the care of nature. They are relevant topics of reflection that help us to see life from a positive mental attitude perspective and an invitation to reorganize our post-pandemic life project.
\end{abstract}

Palabras Claves: autosuperación; vida humana; educación; familia; actitud mental positiva

Keywords: self-improvement; human life; education; family; positive mental attitude 


\section{Introducción}

Para el ser humano como propiciador y solucionador de problemas el panorama de la crisis sanitaria que estamos atravesando, no todo es negativo, sino también podemos vislumbrar de ello cosas positivas por nuestra racionalidad: el entendimiento y la voluntad que poseemos, cuando lo usamos bien nos ayuda a tomar decisiones inteligentes. Esto se ha reflejado en esta coyuntura, pues, se ha enfrentado frecuentemente esta dificultad con prudencia y la solertia, que es "el estar dispuesto para enfrentarse con lo imprevisible" (Polo, 1991). Aunque queramos evadir, tenemos que aceptar la presencia de lo imprevisible y el caos ocasionado por el coronavirus. Asimismo, sacar fortalezas, luces para afrontar y superar las barreras que nos ha impuesto un nuevo estilo de vivencia. En la vida humana muchos problemas son imprevisibles, aunque el hombre es solucionador de problemas, que el animal, no obstante, no posee la receta para ello.

Por otra parte, esta crisis es una oportunidad para mejorar nuestro modus vivendi o estilo de vida y aprender nuevas lecciones vitales: meditar, pensar pausadamente, y reinventar las clases, los negocios, y otras actividades, aprovechando las bondades de la ciencia y la tecnología. No nos hemos quedado con los brazos cruzados. Lo cual va en sintonía con el mensaje del presidente español: "solo quienes creen saberlo todo no aprenderán absolutamente nada de esta traumática experiencia. Los que nos acercamos con humildad, aprenderemos muchas cosas".

Hay mucha literatura e información de distintas dimensiones sobre la difícil situación, que aún seguimos viviendo y experimentando. En esta ocasión, presentamos la otra cara de este hecho coyuntural sin precedente: algunos aspectos positivos; puesto que ya hicimos en un 
artículo aparte (Arango, Chanca y Ñahuincopa, 2020), algunas reflexiones sobre la cara negativa de la pandemia.

El trabajo de investigación se estructura en seis puntos, que consideramos temas significativos desde el abanico de posibilidades: una oportunidad tripartita de reflexión; las bondades de la educación virtual; una invitación a la reforma del sistema sanitario; el fortalecimiento de la vida familiar; el valor y el sentido de la vida humana; y el cuidado de la madre naturaleza. Son lecciones- que van desde un aspecto endógeno hacia el exógeno- para reflexionar mejorar y aprovechar el tempus brevis de la mejor forma posible, viviendo dignamente.

\section{Oportunidad tripartita para la reflexión y el fluir de las ideas}

Aristóteles, en el libro de Metafísica, empieza diciendo: "todos los hombres por naturaleza desean saber" (980 a 22). Para ello, es necesario una información seleccionada con mentalidad crítica y reflexiva ante el cúmulo de noticias que alberga el internet, la televisión y la radio, porque no toda información es verdadera ni objetiva realmente. Este tiempo, como asevera Roberto Rodríguez (2020) es "una oportunidad de oro para la reflexión".

\subsection{Una mirada introspectiva}

Hoy, nos haria un gran bien poner en práctica la frase de Sócrates, que se inspiró en el Oráculo de Delfos: "conócete a ti mismo". Es decir, una reflexión sobre uno mismo, nuestro interior como estuviéramos mirándonos frente a un espejo detenidamente. Responder personalmente a estas preguntas: hasta el momento, ¿qué hemos hecho?, ¿qué dejamos de hacer? y ¿en qué podemos mejorar? Es adentrarnos hacia el interior, hasta el más profundo de nuestro ser. En otros términos, encontrarnos 
con nosotros mismos, haciendo una especie de "examen de conciencia": ver nuestras cualidades, valores o virtudes y también nuestros defectos. Y sopesar entre ellos, como en una "balanza". En esta introspección nos topamos con nuestros "demonios", por ejemplo: el orgullo, la soberbia, la ira, la desidia, la envidia, el odio, el mal genio, el resentimiento, etc., que no nos dejan ser felices. Puesto que "el hombre bueno debe ser amante de sí mismo, con un amor que es contrario al egoísmo cuando se fundamenta en la virtud" (Ñahuincopa 2017). Luego de este breve examen y el descubrimiento de los defectos, es conveniente planificar unas metas concretas para superar y construir nuestro proyecto vital, luchando cada día con nuestros defectos y errores. Esto supone una lucha constante, difícil e incluso hasta el día de nuestra muerte con nosotros mismos. Necesitamos realmente despojarnos de estas miserias que nos hacen míseros o miserables, aunque uno puede sentirse poderoso política y económicamente.

Además, una de las características del hombre inteligente es la reflexividad, que nos da la oportunidad de descubrimos en medio de nuestro mundo interno e íntimo, que es el santuario humano (Yepes y Aranguren, 2003). Lo íntimo es lo más propio de uno y sólo puede conocer uno mismo. Y nadie más puede entrar sin permiso nuestro.

\subsection{Una mirada retrospectiva}

Este enfoque trata de articular la relación de nuestra vida con el tiempo pasado, ¿si realmente hemos aprovechado la oportunidad de vivir dignamente? La vida nos presenta muchas ocasiones para mejorar y crecer en el ejercicio de las virtudes, que nos hacen más humanos y grandes en valores, superando nuestros defectos a pesar de tantas dificultades. Es fundamental ver detenidamente y con calma nuestras 
acciones y omisiones del pasado: ¿qué cosas positivas o negativas hicimos antes de la pandemia y qué dejamos de hacer? Si tuviésemos la posibilidad de volver hacia el pasado, ¿qué acciones buenas realizariamos con vehemencia? Y ¿qué actos no deberíamos cometerlos nunca? Las respuestas nos conllevarian a identificar las faltas o defectos en nuestra vida, al arrepentimiento, a reconocer los daños que causamos a otros involuntaria o intencionalmente y pedirle disculpas o perdón. Pues, como dice la sabiduría popular: el errar es humano y el pedir perdón, divino. Es propio de sabios reconocer sus errores con humildad.

\subsection{La mirada prospectiva}

Nos ayuda a tener un proyecto vital con visión al futuro.

Ante la crisis agobiante, muchas personas se han planteado como salir de esta. Incluso algunos han cambiado de rubro o actividad económica, por ejemplo, en los negocios. Para esta determinación, tuvieron que pensar, reflexionar y hacer algún análisis o rumiar intelectualmente y “pensar más” (Di Berardino, 2020) por la coyuntura que estamos atravesando, evitando una resolución irreflexiva. De hecho, antes de reinventarse, hay que sopesar las cosas, analizando su pro y contra. Alli vuelve aparecer el ingenio humano. Sabiendo que vivimos en un mundo de incertidumbre y que el futuro es incierto, conviene tener un plan de vida: personal, familiar y laboral. Para ello es necesario el orden, como decía Agustín de Hipona: "guarda el orden y el orden te guardará". Por otra parte, ser metódicos nos hace eficaces, siempre en cuando que seamos también flexibles, evitando el encasillamiento. Actuar como personas con sentimiento humano hacia los demás en estos momentos difíciles o críticos y no como máquinas, sin sentimiento ni compasión. 
Somos los únicos seres en el mundo con muchos problemas, pero también con más soluciones al respecto.

Sin embargo, encontramos dos enemigos en estas miradas autorreflexivas o de autosuperación: En primer lugar, la desidia o pereza mental, que obstaculiza la mejora, poniéndonos murallas de conformismo. Por tanto, no se tiene una meta, un objetivo ni mejoramiento, se deja llevar por el ambiente circundante, uno vive por vivir. El otro enemigo es la soberbia, que nos lleva a pensar: que "somos seres perfectos sin errores"; no tenemos por qué y de qué cambiar o arrepentirnos. Puesto que todo está bien. El error lo cometen los demás y nosotros no. Siempre echamos la culpa a alguien antes de asumir la responsabilidad.

Los seres humanos nos equivocamos con muchísima frecuencia. Creemos que el problema más dificil de solucionar es ante todo los personales; puesto que no existe una fórmula o receta para todo ello.

En suma, aprovechar el tiempo para pensar con serenidad, pues, "no podemos pasar por la vida sin reflexionar" (Correa, 2012) especialmente en este tiempo excepcional de la pandemia.

\section{Las bondades de la educación en tiempos de pandemia}

La educación ha tenido un proceso de surgimiento y evolución desde lo natural, urbano y telemática (Echevarria, 1999), cada una de ellas ha salido siguiendo pasos graduales, las que han conllevado a su transformación, aunque hoy en día coexisten simultáneamente en nuestra realidad. Cada uno de estos procesos ha ido consolidándose sin ningún patrón preestablecido como resultado de las ideas surgidas y principalmente del avance tecnológico del momento y del uso de las grandes mayorias. En cada una de las transiciones del paso de un 
proceso a otro, han sufrido alteraciones notables de desconcierto y desorientación; pero el surgimiento de una nueva no anula ni erradica lo anterior y siguen conviviendo: algunos se aferran al cambio por las costumbres o estereotipos creados, mientras que otros viven un proceso de adaptación y aprenden a convivir con lo nuevo.

Por otra parte, la declaración universal de derechos humanos en su artículo 26 señala que toda persona tiene derecho a la educación. La Organización de las Naciones Unidas para la Educación, la Ciencia y la Cultura (UNESCO) menciona que la educación es uno de los principales derechos del ser humano, a lo largo de toda su existencia sin distinción alguna, una educación para todos y de calidad. A esto, se suma el artículo 17 de la Constitución Política del Perú, que hace referencia sobre la obligatoriedad y gratuidad de este servicio en todas las instituciones del Estado.

En el contexto actual en que nos encontramos, generada por la pandemia de la COVID-19: el confinamiento y el distanciamiento social obligatorios para evitar los contagios, lo virtual se ha convertido en un medio necesario de la enseñanza y aprendizaje mundial. Por ejemplo, el teletrabajo que muchas instituciones han implementado, entre otras más, al cual venimos acostumbrándonos. Estos cambios repentinos nos trajeron consigo una nueva experiencia de convivencia entre nosotros mismos, la sociedad y la naturaleza, que nos permiten repensar en todos los aspectos lo que veníamos haciendo antes de la pandemia con visión de futuro.

La pandemia ha marcado un hito histórico en la humanidad, porque ha obligado a todos los gobernantes -autoridades y funcionarios- de los diversos países del mundo a modificar su sistema educativo tradicional al cual estaban acostumbrados: la educación presencial. Del cual migraron a un sistema educativo virtual, a la que denominan también: 
educación a distancia, educación online o en línea y la teleducación. Donde las telecomunicaciones vienen cumpliendo un rol protagónico, a pesar de las precariedades que se viene afrontando en cada una de ellas. Según el informe presentado por la (UNESCO, 2020) sobre la educación en el mundo, se estima que aproximadamente 1600 millones de niños(as), adolescentes y jóvenes no asisten a una escuela.

Esta realidad, aún se complica por la pandemia de la COVID-19, que sorprendió a todo el sistema educativo mundial, donde casi todas las instituciones educativas: escuelas, colegios, institutos y universidades se cerraron por salvaguardar la salubridad; no solo de los estudiantes, sino también de los docentes, padres de familia y otros. Según el reporte dado por la (UNESCO, 2020), un total de 185 paises suspendieron las clases presenciales en todo su territorio nacional, mientras que otros solo lo hicieron de forma parcial. Además, afirman que más del 90\% de la población estudiantil del mundo, fueron afectados y actualmente vienen desarrollando una educación telemática o virtual, gracias a las medidas alternas que tomaron los responsables de cada sector público y/o privado.

La educación peruana, no es ajena a esta situación, porque desde mediados del tercer mes del presente año, ha sido trastocado por la presencia del coronavirus. Es una etapa transcendental que quedará grabado en nuestro inconsciente, pues, ha marcado un antes y un después del sistema educativo nacional e internacional. El proceso de enseñanza y aprendizaje presencial, que se impartía en todo el ámbito nacional en los diversos niveles: inicial, primaria, secundaria, superior técnico y superior universitario de pre y posgrado tanto del sector público como privado, han migrado de forma obligatoria a un sistema de educación virtual telemática o en línea. 
El sistema educativo nacional por medio de las TICs, antes de la pandemia era una propuesta de futuro aún lejano, hoy en día se hizo realidad de forma muy apresurada, por lo que se hace ineludible realizar una reflexión o análisis sobre los procesos de educación telemática y en linea que se viene desarrollando a nivel nacional en todas las instituciones educativas. En ellas se vienen implementando procesos de aprendizaje, aplicando enfoques basados en la virtualización de algunas de sus actividades como las videoconferencias (Hodges, Moore, Lockee, Trust y Bond, 2020).

También es necesario entender que la educación online ha llegado para quedarse; puesto que ha roto esquemas de estilos y modos de enseñanza y aprendizaje establecidos hasta antes de la pandemia, acelerando la implementación de nuevos procesos y tecnologías no solo para los estudiantes, sino también para los docentes, quienes han sufrido un proceso de adaptación y potenciación en el rol académico y formador para enfrentar el cambio disruptivo a estos nuevos escenarios.

Ante la crisis, las respuestas de las instancias responsables y de los mismos docentes inicialmente fueron entre otras cosas: el de tomar una posición pasiva o seguir haciendo lo que realizaban en la modalidad presencial; sin embargo, primó las pautas emanadas del Ministerio de Educación, que permitió afrontar la situación como la implementación de la educación "yo aprendo en casa" para inicial, primaria y secundaria, las cuales son impartidos por los medios de comunicación masivo, como la televisión y la radio, al cual refuerzan los docentes mediante el uso de los medios electrónicos y las redes sociales. Mientras que para el nivel superior universitario por las normas que amparan han contratado servicios de plataformas virtuales para impartir una educación online o también denominado e-learning. 
Este proceso de migración de un sistema de educación presencial a la virtual ha consistido en adaptar esquemas del modelo presencial a la presencialidad virtual, sin darle lugar a la reflexión de cómo hacerlo (Gisbert, 2020), porque el tiempo era apremiante y las condiciones situacionales no garantizaban ni siquiera para realizar procesos de capacitación. La educación online, que refiere al uso de tecnologias, no es igual a un aprendizaje y enseñanza a distancia, ya que la "distancia" en estos contextos de comunicación virtual es relativa; de la cual cabe recapacitar: solo nos separa 30 centímetros de la pantalla del computador, celular o Tablet como refiere (Carrasco, Baldivieso y Di Lorenzo, 2016).

Por ello, podemos señalar que la tecnología implementada para fomentar la educación virtual también tiene numerosas bondades como (García, 2017) señala los siguientes:

- El alumno como protagonista principal de su aprendizaje, trató de planificar responsablemente su tiempo para trabajar a su ritmo y decidir el cuándo, el cómo y el con qué estudiar; pues la virtualidad ayuda a desarrollar y fortalecer a cada estudiante los procesos autónomos de aprendizaje. Asimismo, requiere que los temas sean asequibles para que pueda aprender.

- Los instrumentos de comunicación virtual ayudaron generar un lazo de confianza entre el maestro y el estudiante, cultivando los valores de respeto, solidaridad y amistad; algunas veces compartiendo experiencias interculturales.

- La modalidad virtual involucró de una forma activa a los padres de familia que fueron los cooperadores de educación en cada uno de sus hogares, por ejemplo, a nivel inicial y primario. 
- El mundo virtual ofreció muchas posibilidades, tanto para el alumno como al profesor para la comunicación y manejo de información a través del uso de distintas plataformas tecnológicas, adquiriendo estrategias para crecer en la excelencia a nivel personal y social.

Estas ventajas que refiere García están en el marco de los objetivos del sistema educativo actual, ligado al desarrollo de habilidades para “aprender a aprender" concepto que fue acuñado por Novack y Gowin en su obra Aprendiendo a aprender (1988), se basa en los planteamientos que vierte Ausubel sobre el aprendizaje significativo, del cual Patarroyo y Navarro (2017) señalan que es una habilidad superior a la metacognición.

El proceso de aprendizaje en la etapa de aislamiento nos ratifica que la mejor educación es autónoma, desarrollando creativamente las capacidades de aprendizaje en sociedad e individualizada, proceso que te permite ser un aprendiz estratégico interactivamente como refieren (Pardo y Cobo, 2020).

\section{Intento de superación de la precariedad del sistema sanitario}

Como sabemos el sector más afectado por el coronavirus fue la salud pública. El virus de Wuhan hizo colapsar realmente a los mejores hospitales del mundo, que el Perú con su sistema de salud precario tuvo que enfrentar con muchas desventajas que el resto de los países. Dicho de otra manera, como refiere (Maguiña, 2020), "esta pandemia de la COVID-19 hoy en dia ha demostrado que todos los seres humanos somos iguales, no hay pais tranquilo en el mundo, salvo las tribus no contactadas". Durante los meses que duró la cuarentena, las conversaciones familiares en los hogares han girado en torno a la salud. Así, ha salido a flote, muchas deficiencias, lo que requirió enfrentar, de forma organizada (Gozzer, Canchihuamán \& Espinoza, 2020). 
Sin embargo, en esta coyuntura critica hay unas cuantas cosas destacables en el campo de la salud: En primer lugar, el desempeño sacrificado que hicieron y siguen realizando los médicos, las enfermeras y todo el personal de salud que vienen cumpliendo con su función de salvar vidas humanas en el campo de batalla.

Por otra parte, se intentó unificar y articular por primera vez la labor del Minsa y EsSalud, con la finalidad de mejorar la atención a los usuarios, intento que conllevó involucrar también otros sectores de la población. Fruto de ello surgió la conformación del grupo "Comando Covid-19", que fue parte de una politica nacional. Este fue replicado en los gobiernos regionales, provinciales y distritales, y que ha tenido relativamente un papel preponderante, para la sensibilización y el aislamiento social.

También es meritorio mencionar, los proyectos propuestos, a través del Consejo Nacional de Ciencia, Tecnologia e Innovación Tecnológica, Concytec, que se han presentado más de 1000 propuestas innovadoras, dentro de los cuales se ha priorizado los siguientes:

"los proyectos de alto impacto, de corta maduración, con equipos que ya estén consolidados en 6 áreas de la pandemia: detección rápida, segura y a escala mayor a un precio cómodo, los diversos accesos sanitarios, para un reporte virtual, de vacunas y que estos contengan estudios epidemiológicos-moleculares para descifrar el virus".

Todo esto fue un gran desafio para la ciencia médica y los investigadores, quienes no podian ser ajenos, como señala (Garay, 2020).

A ello, se adhieren algunos especialistas como muestra (Ortiz, 2020) al recoger las declaraciones del exministro de Salud Óscar Ugarte, de que "es la gran oportunidad, de grandes enseñanzas y, para aprovechar de 
cómo mejorar el sistema de salud. Es el escenario adecuado para que se retome y se enlace ciencia y salud que antes estaban reservados solo para el mundo de la ciencia, o para la medicina en particular". Porque la vida ha cambiado sustancialmente, después de este ataque invasivo de la COVID-19.

Se sugiere al Ministerio de Salud, y las Direcciones Regionales de salud, que, cada región debe contar con un hospital de tercera categoría -donde estén agrupados el sistema sanitario más completo como: hospitales y clínicas de mayor cubertura-, solo así tendría la capacidad de afrontar cualquier pandemia futura. Es una propuesta general y relevante, para que todos los partidos políticos, así como las autoridades y funcionarios del sector, realicen un gran esfuerzo de confluir ideas, para equipararnos con nuestros pares de América del Sur, porque la brecha es muy abismal. Después de esta crisis sanitaria, debemos acortar esas grandes diferencias; pero con una planificación a corto, mediano y largo plazo. Solo así estaremos en la capacidad de ofrecer una atención integral de salud, a todos los usuarios de este sector.

Otro dato tan necesario, es que hemos tenido poco presupuesto como señalan, del 2.2\% del producto bruto interno -PBI- como reporta el diario oficial (El Peruano, 2020), a partir de la fecha, de acuerdo a los especialistas, cada año, se debe incrementar el presupuesto de forma paulatina, con la finalidad de atender a toda la población en general. Casi en la parte final de la cuarentena, si hizo el intento de coordinar el trabajo, para la atención acelerada de los enfermos, junto a las clínicas particulares, una acción que se logró en plena crisis.

Nos podemos hacer una interrogante: después de la pandemia ¿qué pasará con el sistema de salud? En relación a la pregunta expuesta (Maguiña, 2020) puntualiza: 
"que pasada la epidemia se exigirá al Estado Peruano, el inicio de una profunda reforma sanitaria, que apunte a un sistema único y universal de la salud, integrado y coordinado, donde se retome el rol rector del Ministerio de Salud, y que además se cuente con recursos económicos sólidos y reales, que sirvan a su vez para tener una red nacional de laboratorios modernos, integrada y de excelente calidad en beneficio de toda la Sociedad Peruana".

En esta batalla titánica, se ha visto la solidaridad de muchas personas e instituciones, que han puesto el hombro y han aportado económicamente y con materiales -oxígenos, respiradores e implementos de seguridad- para el personal de salud y las fuerzas armadas, que han sido los más vulnerables como refiere (Quiroz, Pareja, Valencia, Enríquez, De León y Aguilar, 2020), ya que los datos como sostiene (Alayo, 2020) “de cada 200 médicos, uno sé atendió y murió por la COVID-19”, porque estaban comprometidos e hicieron una labor encomiable.

La población en general, para salvaguardar la integridad y salud, han intentado guardar la cuarentena rígida y focalizada, y cuidar el distanciamiento social, el uso adecuado de las mascarillas, el correcto lavado de las manos etc., que, de alguna manera, contribuyeron el descenso de personas contagiadas.

\section{Fortalecimiento de la unidad familiar y la Salud mental y espiritual}

Según (Hijós y Esmoris, 2020), la incertidumbre a nivel mundial puso de relieve tanto una fragilidad de los cuerpos y las casas en tiempo de "normalidad en aislamiento" como tensiones vinculadas a la solidaridad y la sospecha en los lazos sociales. 
Antes de la pandemia, casi la gran mayoría vivía, muy "ocupado" en su trabajo, pensando solo en el hoy planificando el futuro. Sin embargo, todos estos sueños, se fueron disipando con el coronavirus, que nos ha tenido en velo por varios meses y confinados en nuestros hogares.

Estando en retiro obligatorio, cada uno en sus hogares, empiezan a repensar el verdadero sentido de la vida. Esta situación tan adversa nos conlleva a tener mayor contacto con los miembros de la familia, en el hogar. Muchos hogares se organizaron a convivir horas y dias, que implica la ayuda mutua y la solidaridad con los menos poseídos. Allí, empieza a fortalecerse la unidad familiar, que genere la confianza, y ayude a vislumbrar el horizonte de una forma más promisoria. Esta pandemia, ha sido una ocasión para reforzar la unión familiar, que es un atributo que tiene el ser humano, porque la familia, que siente y sufre; por lo que, todo tipo de ayuda recae sobre ella misma.

En esta coyuntura, se ha percibido un ambiente de unión familiar; porque empezaron a convivir, sobrellevar y compartir las alegrias, las tristezas, preocupaciones, necesidades y el dolor con los hijos, la esposa, los abuelos, etc., y lo que más resaltó fue el mayor tiempo de disposición de todos ellos. Para los padres de familia, fue una circunstancia propicia, retomar el rol protagónico de ser el "educador": platicar, enseñar, escucharlos y jugar con ellos, en definitiva, pasar más tiempo con los hijos, que quizá por el trabajo, el distanciamiento y otros factores que no era factible cumplir con este deber sagrado. Antes talvez era suficiente con comprarles los útiles escolares, luego el resto se encargaba el profesor. Ahora, el padre de familia tiene que ayudar, por ejemplo, en inicial y primaria, participando activamente cada día del programa "aprendo en casa" juntamente con el hijo/a pequeño. Además, con las tareas que envía el profesor/a y la retroalimentación. Es una nueva experiencia, el estar casi todo el día dedicándoles a ayudar en sus 
estudios, que alguna vez fue fatigoso, pero vale la pena ver los aciertos y desaciertos en el aprendizaje de la prole.

La gran mayoría de la población, por sus diversas actividades laborales, se sentía demasiado ocupado, con la frase típica: "que no alcanza el tiempo". Esta pandemia nos ha hecho entender, que es necesario repensar la forma como estamos viviendo, sin prestar atención a la grandeza y el valor de la familia, pues, cuán importante son para los padres, el amar, cuidar, corregir y protegerlos a los seres queridos.

Estamos acostumbrados a vivir tan alocados, tan apurados, que supuestamente, no "tenemos tiempo". Esta oportunidad, nos permite entender, que somos seres mortales y seres pasajeros que estamos de paso por este mundo. Es un tiempo ideal para ver las cosas desde una óptica diferente: desde una perspectiva transversal, empecemos a valorar las personas en su verdadera magnitud, mientras aun esté en vida, porque después, es algo utópico, mucho va depender de las actitudes, que asumamos para tener una verdadera calidad de vida, y armonía que debe florecer en el hogar.

La forma de cómo entendemos la vida, se cambió todo, esto supuso un nuevo orden, de estar más preocupados por las noticias, que informaban de los contagios y las muertes como consecuencia de la COVID-19. Entonces, cada familia se acomodó y buscó, de cómo cuidarse.

Estos momentos cruciales, las familias empezaron a valorar la importancia de los medios de comunicación como la radio; que en algunas familias ya había pasado de moda, pero con las nuevas prerrogativas, en lo concerniente a la educación, como es el caso “aprendo en casa", los medios de comunicación empezaron su verdadero rol de informar; como la televisión y el celular; que hace tiempo llegaron a formar parte de nuestra forma de vivir. 
Por otra parte, muchas familias han tenido que acomodarse a un estilo de vida diferente, como es el trabajo remoto, asumir y asimilar la pérdida de un familiar, y la ausencia fisica de algunos miembros, puesto que no podian visitarse. Pero en esas circunstancias hubo cosas positivas en mayor medida: la reconciliación, el diálogo, el preocuparse los unos por los otros, el cultivo de detalles de amor familiar -con la disyuntiva que en cualquier momento uno podría contraer la enfermedad y que pueda morir- y también es destacable la solidaridad y generosidad entre la gente más humilde.

\section{El valor de la vida y la dignidad}

Partimos esta reflexión de un diálogo cotidiano. Un día, al saludar un amigo a otro compañero: ¡buenos días! Escuché un interrogante, ¿qué bueno trae el dia? Me vino a la cabeza, que al menos estamos vivos, con salud y trabajo, mientras otros cómo estarán. Este saludo es profundo, pues, conlleva a una interpelación con otra persona igual que tú, con problemas, dificultades y preocupaciones. Al saludarle, con estas dos palabras: le deseamos una buena salud, tranquilidad, equilibrio emocional y todo lo mejor. Y que es una señal de que uno está vivo. Y sólo nos pide que seamos agradecidos por la vida.

El confinamiento que nos tocó vivir, ha sido oportuno para leer, escribir y reflexionar sobre los diversos temas que nos atañen cada día. Algunas veces, estas reflexiones, aunque pocas, han sido profundas. Es interesante interrogarnos de mano a la filosofia: ¿quiénes somos? ¿de dónde venimos y a dónde vamos? ¿Qué sentido tiene nuestra vida personal? Después de la pandemia cómo nos gustaría tener nuestro proyecto vital. 
Lo más valioso que tenemos en este mundo -con y sin pandemia- $\sin$ lugar a dudas es la vida humana. Pero qué tipo de vida nos gustaría vivirla seguramente aquella vida que esté concorde con nuestra condición de seres inteligentes: una vida que se construye a base de lucha interior contra nosotros mismos, estos son: el mal genio, la soberbia, el egoísmo, etc. Así valdrá la pena existir en este mundo como refiere Marcel en su Diario Metafísico del 28 de noviembre del 1931: "Hay algo que se llama vivir y algo que se llama existir: yo he escogido existir..."

Después de esta dificil situación es conveniente valorar y respetar la vida de uno mismo y de los demás. ¿Y qué es la vida? Para tratar de responder esta cuestión nos apoyamos en uno de los grandes genios griegos. Aristóteles, en su tratado De anima, define al ser vivo como automoverse, esto es, lo que se mueve sin necesidad de un agente externo que lo impulse, en pocas palabras "para los vivientes, vivir es ser" (415b 13). Asimismo, el Estagirita no puede concebir la vida sin acudir a un principio determinante: el alma. Precisamente los tratados biológicos mayores del filósofo griego incluyen el De anima, el más importante de todos, dedicado al estudio de la vida, y en donde se contiene la concepción aristotélica del alma como "la entelequia primera de un cuerpo natural que en potencia tiene vida" (2008: 412 a 30). Un cuerpo natural significa un cuerpo organizado y esto "se compone de una materia y de un alma que informa esa materia" (Ñahuincopa, 2014). Esta, sin embargo, es una definición genérica que se refiere al alma vegetativa, sensitiva o racional. De igual modo, somos conscientes de que, hay algo en nosotros un deseo por vivir, perpetuación de la especie y un temor a la muerte. El hombre como los animales tiene un instinto de conservación de la vida y de la especie. Vive en comunidad, rodeado de muchos seres vivos, que forman parte del reino animal y vegetal. 
La vida ya sea vegetal, o animal y especialmente la humana es un don o un regalo de valor infinito. Puesto que es algo que se nos ha dado sin contar con nosotros. ¿Y quién nos ha regalado? Solo un "Ser" que tenga poder y amor. Filosóficamente, esto nos lleva a preguntarnos por la causa, pues, no es fácil, concebir la vida humana tan compleja como ella misma es, -libre, espiritual y trascendente- que sea solo producto de la materia. La materia funciona a base de leyes fijas, porque se realiza de una manera determinada. Nacemos, no tenemos capacidad para escoger, y nada podemos rehusar. Son otros quienes dibujan, diseñan, garabatean y proyectan sobre el papel de nuestra vida. (Wilson, 1983). Si la vida es un don agraciado que debe motivar en la persona humana un eco de agradecimiento y saber valorarla.

Por otra parte, la vida humana está intimamente relacionada con la moral, pues, tiene un sentido ético. Es decir, obrar el bien de acuerdo a nuestra naturaleza. El hombre actúa por fines e intereses. El fin supremo es buscar la felicidad. Esto lo consigue obrando el bien a base de prácticas o de actos buenos, denominado virtud y evitando en la medida de lo posible los vicios. "Es a la vida a quien nosotros pediremos el principio de la moralidad" (Guyau, 1944). Es esencial entender el sentido que damos a nuestra vida, que garantice y nos permita vivir con calidad humana. En algunas ocasiones, absorbidos por el trabajo, el ambiente externo y el bombardeo de programas poco educativos en la televisión y en el internet, tratamos de vivir por vivir pasotamente sin ningún horizonte. Es interesante encontrar el motivo de vivir como sostiene Mounier (1965): "querer vivir a cualquier precio es aceptar un día vivir al precio de las razones de vivir". ¿Y esto cuándo se logra? Cuando realmente somos conscientes de la vida que nos hemos proyectado, creciendo internamente en los pilares de nuestra existencia: las virtudes y valores. "Solo existimos definitivamente desde el momento en que nos 
hemos constituido un cuadro interior de valores o de abnegaciones contra el cual, sabemos, ni siquiera prevalecerá la amenaza de la muerte" (Ibidem). El fundador de Logoterapia, Víctor Frankl, que ha puesto en práctica todo lo que estamos exponiendo y ha vivido en carne propia en el campo de concentración de Auschwitz testimonia sobre el sentido de la vida y solo el hombre es responsable de esta historia, como lo explica brillantemente:

"Como quiera que toda situación vital representa un reto para el hombre y le plantea un problema que sólo él debe resolver, la cuestión del significado de la vida puede en realidad invertirse. En última instancia, el hombre no debería inquirir cuál es el sentido de la vida, sino comprender que es a él a quien se inquiere. En una palabra, a cada hombre se le pregunta por la vida y únicamente puede responder a la vida respondiendo por su propia vida; sólo siendo responsable puede contestar a la vida" (Frankl, 1985).

Para el hombre, como sabemos existen algunos enigmas. Uno de ellos es la vida. Es dificil comprender racionalmente la realidad de la vida humana. ¡Es un misterio! Ante el cual necesitamos asombrarnos como los primitivos pensadores que hicieron sobre la naturaleza (Ñahuincopa, 2020). Hay una dificultad en articular las características de auto posición con la autotrascendencia y realización de la vida (Sanabria, 1987).

La vida humana es un proyecto vital. Para Ortega y Gasset (1958) "el hombre no es cosa ninguna, sino un drama su vida, un puro y universal acontecimiento que acontece a cada cual, y en que cada cual no es, a su vez, sino acontecimiento". Esto no significa que la esencia humana sea "volátil" o que no sea nada, hay algo, al menos la existencia. Sobre este cimiento se tiene que construir el proyecto vital. El ser humano no es algo estático, fijo, invariable y dado; no sólo tiene que hacerse a sí mismo, sino determinar lo que va a ser. Lo único que el hombre tiene de ser es lo que 
ha sido, esto y lo otro. Eso es vivir. En resumen, el hombre no es, sino que va siendo (Ibid). Esa esencia humana no está acabada, pero tiene el cimiento. La vida humana se fuera nada y solo estuviera haciéndose, dónde radicaría su dignidad.

Otro aspecto, para Marcel, somos homo viator, esto es, peregrinos, viajeros en este mundo en busca de la verdad (Pereira, 2020). Este pensamiento nos conlleva a profundizar también que no somos eternos en este mundo; tampoco somos dueños del transcurrir del tiempo, intentamos ganar a éste (Polo, 1991). El tiempo que nos toca vivir es poco, que debemos aprovecharlo, haciendo las cosas de la mejor manera para que podamos morir dignamente. Y la filosofia nos prepara a aprender morir bien, pues, como dice Montaigne: filosofar es aprender a morir.

El hombre es temporal, además, es el único ser del universo, que puede trascender en el tiempo con el conocimiento y amor.

\section{La nueva actitud del hombre frente a la naturaleza}

La relación entre el hombre y la naturaleza siempre ha existido desde los albores de la historia, una relación donde los primeros interactúan con el segundo, inicialmente algunos hombres adjudican la idea de que la naturaleza fue creada por Dios. Heisenberg, Gabriel, y Pascual, (1969) consideran como iniciadores de esta propuesta naturalista a Kepler, Galileo y Newton. Esta idea en su proceso de evolución logra mutar al señalar que existe la influencia de la ciencia y la técnica en la naturaleza el cual viene causando su transformación. De allí, Barros (1999) habla de otra perspectiva: la historia económica de que el hombre domina la naturaleza. Pero la realidad en que vivimos hoy en día nos muestra diversos aspectos, donde perviven las creencias y prácticas, desde las consideradas paganas, conservacionistas y transformadoras, aspectos 
que hoy en dia han sido trastocadas por un problema fundamental, generada por la COVID-19.

Este problema, hoy en día se ha convertido en el principal desafio de toda la humanidad, como señala (Tolentino, 2020) hablar de cuarentena en la actualidad es volver al pasado. Hecho que nos ha mostrado a todos como señala Carrón (2020) que estábamos viviendo en una burbuja creyéndonos omnipotentes protegidos por la ciencia y la tecnología. Aspectos que viene influyendo directamente en el cambio de nuestras actitudes y comportamientos, obligándonos a adoptar el uso de mascarillas, protectores, así como mantener el distanciamiento social, aspectos básicos que permiten garantizar la subsistencia de nuestras vidas, en cumplimiento de normatividades emanadas. También hizo que los grandes empresas y laboratorios del mundo, así como los gobiernos de cada uno de los países afectados destinen ingentes cantidades de recursos económicos para poder hacer frente a este problema, hecho o resultado que se trasluce en la actualidad, con la presentación competitiva de las vacunas de los principales laboratorios, que a su vez vienen generando una serie de reacciones y especulaciones de parte de la población, en quienes se observa opiniones divididas a favor y en contra.

Si imaginariamente nos trasladamos a inicios del año 2020 donde reinaba la normalidad, los saludos efusivos entre las personas, la abundancia de los diversos productos en el mercado, entre otros. Hoy en día gracias a la COVID-19, ha cambiado talvez para siempre, porque las diversas formas de vida o roles que veníamos cumpliendo en cada instancia ya sea de forma individual o colectiva ya no son lo de antes, al estar enfrentando un proceso de cambio de comportamiento generalizado que perdurará entre nosotros. Las cuales nos conlleva a preguntarnos ¿Cómo ha cambiado nuestra forma de pensar, sentir y actuar? Las 
respuestas que podemos obtener de ellas nos conllevarán a repensar, diseñar, construir y ejecutar según nuestras necesidades y deseos creativamente nuevas formas de vida.

A ello no se escapa la relación intrínseca que tiene entre hombre y la naturaleza, espacio donde desarrolla las diversas actividades que garantizan su subsistencia, dependiendo de la cosmovisión que le ha impregnado o influido en su cotidianidad desde sus generaciones antecesoras, las cuales permitirán mostrar su actitud y comportamiento con respecto a la naturaleza. La cosmovisión andina que aún pervive entre nuestras comunidades rurales, da vida y muestra respeto frente a la naturaleza, en todo su quehacer productivo, mientras que las que tienen influencia de la ciencia moderna consideran que la naturaleza, no tiene vida por lo que debe estar bajo el dominio del hombre.

\subsection{El sentir del hombre frente a la naturaleza}

La etapa de desconfinamiento en que nos encontramos nos abre nuevos retos que conlleven a enfrentarlas con mucha responsabilidad ya sea de forma individual o colectiva temas como: el fenómeno del cambio climático, la perdida de la biodiversidad y la gestión sostenible de los residuos como refiere (Serrano, 2020). En este periodo de confinamiento hemos sido protagonistas de nuevas formas de comportamiento, obligando al hombre frente a la naturaleza. Porque los centros comerciales estaban cerrados, las grandes calles o avenidas lucian vacías, las diversas áreas de recreación se hallaban cerradas, entre otros, donde la vida agitada del hombre tuvo un momento de sosiego. Permitiéndonos observar desde dentro -ventanas, balcones, azoteas- lo que venía ocurriendo fuera; de esa experiencia podemos señalar: que solo 
bastó un corto periodo de paralización para que la naturaleza cambie, se rehabilite y vuelva a su estado normal.

Escenario que nos brinda la oportunidad para proponer iniciativas de una nueva relación entre los seres humanos y la naturaleza -plantas, animales, minerales- entendiendo que lo humano se construye a expensas de la naturaleza, las cuales son sentidos y reconocidos por los actores sociales

\subsection{El pensar del hombre frente a la naturaleza}

Nunca antes como ahora, la presencia de una enfermedad como la COVID-19, había ocupado un espacio primordial en nuestros pensamientos. Todos los días, los medios de comunicación: escrita, hablada y televisiva -además de las diversas redes sociales- han saturado con información objetiva, subjetiva y relativa con relación al virus de Wuhan; mostrando datos estadísticos, testimonios de casos emblemáticos que influenció en la forma de pensar de la población, y con ello se incrementó los niveles de ansiedad y estrés que afecta la salud mental.

Por otra parte, esta pandemia, en un corto tiempo nos mostró los impactos positivos como: la mejora de la calidad del aire, del agua, debido a la reducción de emisiones de gases y de residuos industriales y urbanos. Asimismo, es una oportunidad que se presenta para construir una nueva sociedad humana, pacífica y ecológica; una nueva economía, que esté orientada a preservar la salud de la naturaleza.

Para que la humanidad, tome conciencia, aún requiere experimentar cambios radicales. En el corto tiempo se ha observado, cambios sustanciales en la naturaleza. Ha sido una magnífica oportunidad, para retomar experiencias ancestrales como la práctica de la solidaridad que 
nos permitieron afrontar el problema, así como la aceptación de las restricciones de ciertos derechos con la finalidad de evitar la propagación del virus. Estos hechos nos abren una esperanza para iniciar un proceso de cambio partiendo desde nuestros hábitos cotidianos de producción y consumo, la que conllevará a la protección y cuidado de la naturaleza como el bien común para garantizar su sostenibilidad.

\subsection{El actuar del hombre frente a la naturaleza}

El desarrollo vertiginoso de la ciencia, la tecnología y el conocimiento, no son suficientes para garantizar la subsistencia del hombre en la actualidad, hay que entender que dependemos del agua, el aire y el alimento que nos brinda la madre naturaleza. Entender esta relación fundamental entre hombre y el medio ambiente, nos permitirá garantizar la preservación de la biodiversidad y de nuestras proles.

Está en asumir en cada uno de nosotros acciones concretas que garanticen salvaguardar la vida del hombre y la naturaleza, no solo guardando la distancia social como hoy lo venimos realizando en nuestros domicilios. También nos compromete una gran responsabilidad moral a cada uno de nosotros por ser un integrante más de la naturaleza de quienes nos diferenciamos por ser seres pensantes que podemos actuar con responsabilidad y racionalmente en el uso de los recursos naturales para remediar el ambiente impactando positivamente en los otros. 


\section{Conclusiones}

Esta pandemia, ocasionada por el coronavirus, tiene dos caras: por una parte, es una crisis que trastocó a la humanidad entera en sus diversas dimensiones y actividades, poniéndonos en el aislamiento social obligatorio y el cuidado de bioseguridad con el uso correcto de las mascarillas, el lavado adecuado de las manos y la guarda de la distancia social. Por otra parte, es una ocasión propicia para la reflexión intelectual como seres inteligentes sobre nosotros mismos, el valor y sentido de la vida humana, y la reinvención de las actividades económicas, académicas y otros. Asimismo, para sopesar el sistema de salud y su proyección al futuro, que el Estado invierta más recursos; el valor de la unidad familiar y subrayar cuán importante es el cuidado del medio ambiente.

Durante la pandemia, el sistema de salud, ha estado lidiando y adaptándose a este Coronavirus, con todas las deficiencias, ha brindado todas las atenciones y asistencias necesarias, con la finalidad de salvaguardar la vida humana. La familia es la parte medular de la sociedad, que ha estado en toda la vicisitud de la pandemia, que ha sido una oportunidad para el fortalecimiento de la unión familiar: la comprensión, tolerancia, amor, perdón, diálogo y otros; aunque existió también algunos casos de separaciones.

La educación virtual, antes de la pandemia era una posibilidad a futuro, hoy es una realidad, donde los sectores públicos y privados encargados de brindar este servicio, de formación básica y superior, vienen afrontando la transición de la educación presencial a la virtual, rompiendo con estructuras educativas tradicionales y dar paso a nuevos paradigmas educativos, construyendo una nueva historia educativa desde la crisis que nos tocó vivir. 
Finalmente, la COVID-19 nos mostró a toda la humanidad un hecho sin precedentes del cual somos testigos de haber vivido una experiencia inolvidable de sufrimiento y dolor, a la vez nos muestra una nueva realidad, lleno de nuevas perspectivas y retos que permitan forjar una nueva relación de convivencia armónica entre el hombre y la naturaleza que está perdiéndose, para ello es necesario sopesar para equilibrar la actitud omnipotente de la ciencia y la tecnología heredadas desde la modernidad, las cuales aún están lejos de protegernos de estos problemas. 


\section{Referencias}

Arango Olarte R., Chanca Flores A. \& Ñahuincopa. (2020). Pandemia y crisis en Huancavelica - Perú desde la perspectiva fenomenológica, antropológica y filosófica. Revista Científica Arbitrada de la Fundación MenteClara, Vol. 5 (174). DOI: https://doi.org/10.32351/rca.v5.174

Alayo, Orbegozo Fernando. (Lima, 11 de octubre de 2020). Uno de cada 200 médicos peruanos que atendió la pandemia falleció por COVID-19. https://elcomercio.pe/autor/fernando-alayoorbegozo/

Aristóteles. (2008). De anima. Sobre el alma, T. Calvo (ed.). Madrid: Gredos.

Barros Guimerans, C. (1999). La humanización de la naturaleza en la Edad Media. Edad Media: revista de historia, (2), 169-194.

Carrasco, S., Baldivieso, S., \& Di Lorenzo, L. (2016). Formación en investigación educativa en la sociedad digital. Una experiencia innovadora de enseñanza en el nivel superior en el contexto latinoamericano. Revista de Educación a Distancia, (48). Recuperado a partir de https://revistas.um.es/red/article/view/253481

Carrón, J. (2020). El despertar de lo humano. Reflexiones de un tiempo vertiginoso. Milán, Italia: BUR Rizzoli [versión e-book]. Recuperado de https://it.clonline.org/cmfiles/2020/12/23/eldespertardelohumano.pdf.

Correa Lozano, L. (2012). "La enseñanza de la filosofia y sus contribuciones al desarrollo del pensamiento". Sophia, Colección de Filosofia de la Educación, (12), 67-82.

Decreto Supremo No 002-99-TR Aprueban el Reglamento de la Ley No 27056, Ley de Creación del Seguro Social de Salud

Di Berardino, M. A. (2020). "Filosofia rumiante: una reflexión cosmopolitica sobre la pandemia". Das Questôes 8.

Diario Oficial El Peruano. (30 de julio, 2020). Presupuesto histórico https://elperuano.pe/noticia/100391-presupuesto-historico

Echeverría, J. (2000). Educación y tecnologías telemáticas. Revista iberoamericana de educación, 24, $17-36$

Frankl, V. E. (1985). El hombre en busca de sentido, 6a. ed., Barcelona, Herder

Garay, R. Karina. (17 de agosto, 2020). Concytec: conoce a las instituciones peruanas que hacen ciencia contra el coronavirus. https://andina.pe/agencia/noticia-concytec-conoce-a-lasinstituciones-peruanas-hacen-ciencia-para-enfrentar-al-covid19-809849.aspx

García, L. (2017). "Educación a distancia y virtual: calidad, disrupción, aprendizajes adaptativo y móvil”, Revista Iberoamericana de Educación a Distancia, 20 (2), pp. 9-25. Disponible en: https://www.redalyc.org/articulo.oa?id=3314/331453132001

Gisbert, M. (2020). "Hacer virtual la docencia no debe ser hacer presencial la virtualidad", Portal de noticias de la URV. Disponible en: http://diaridigital.urv.cat/es/h acer-virtual-la-docencianodebe-ser-hacer-presencial-lavirtualidad/

Gozzer, E., Canchihuamán, F., \& Espinoza, R. (2020). COVID-19 y la necesidad de actuar para mejorar las capacidades del Perú frente a las pandemias. Revista Peruana de Medicina Experimental y Salud Pública, 37(2). doi: https://doi.org/10.17843/rpmesp.2020.372.5410

Guyau, J. M. (1944), Esbozos de una moral sin obligación ni sanción, Buenos Aires, Americalee. 
Heisenberg, W., Gabriel, A., \& Pascual, F. (1969). La imagen de la naturaleza en la fisica actual. Seix Barral.

Hijós, N. y Blanco Esmoris, M. F. (2020). La adaptación a la supervivencia: cuerpos y casas durante el aislamiento. Reflexiones sobre la vida cotidiana en los sectores medios del Área Metropolitana de Buenos Aires. Revista Científica Arbitrada de la Fundación MenteClara, Vol. 5 (167). Doi: https://doi.org/10.32351/rca.v5.167

Hodges, C., Moore, S., Lockee, B., Trust, T. y Bond, A. (2020). La diferencia entre la enseñanza remota de emergencia y el aprendizaje en línea. Educause Review, 27.

Maguiña Vargas, C. (2020). Reflexiones sobre el COVID-19, el Colegio Médico del Perú y la Salud Pública. Acta Médica Peruana, 37(1), 8-10. doi: http://dx.doi.org/10.35663/amp.2020.371.929

Mounier, E. (1965), El personalismo, 2a. ed., Buenos Aires, EUDEBA.

Novak, J. y Gowin, D. (1988): Aprendiendo a aprender, Barcelona, Martinez Roca.

Ñahuincopa Arango, A. (2014). "La inmortalidad del alma en Aristóteles según la escolástica barroca: Báñez, Toledo, Suárez", Cuadernos de Filosofia. Excerpta e dissertationibus in philosophia, Vol. XXIV, 95-197.

Ñahuincopa-Arango, A. (2017). “¿Sostuvo Aristóteles la inmortalidad del alma? La respuesta de Suárez". Scientia et Fides, Vol 5, N 1, 267-290.

Ñahuincopa Arango, A. (2020). Los tres problemas filosóficos en el pensamiento primitivo. Revista Cientifica Arbitrada de la Fundación MenteClara, Vol.5 (197). doi: https://doi.org/10.32351/rca.v5.197

Ortega y Gasset, J. (1958), Historia como sistema, Madrid, Revista de Occidente.

Ortiz, Bisso Bruno (12 octubre de 2020). declaraciones del exministro Óscar Ugarte Ubilluz. https://elcomercio.pe/tecnologia/ciencias/mentes-peruanas-pandemia-covid-19-peruentrevista-oscar-ugarte-la-investigacion-no-estaba-alineada-con-la-salud-publica-noticia/

Pardo, H. y Cobo, C. (2020). Expandir la universidad más allá de la enseñanza remota de emergencia. Ideas hacia un modelo híbrido postpandemia, Barcelona, Outliers School.

Patarroyo, C. y Navarro, M. (2017). “Aprender a aprender: La apuesta pedagógica de la Universidad del Rosario", Reflexiones Pedagógicas, Urosario, pp. 1-8.

Pereira Ríos, D. (2020). El existencialismo de Gabriel Marcel. Aspectos de la verdad desde la filosofía concreta. Revista Espiga, 19 (39), 131-147.

Polo, L (1991). Quién es el hombre, Madrid, Rialp.

Quiroz Carrillo, C. G., Pareja Cruz, A., Valencia Ayala, E., Enriquez Valencia, Y. P., De Leon Delgado, J., \& Aguilar Ramirez, P. (2020). Un nuevo coronavirus, una nueva enfermedad: COVID-19. Horizonte Médico (Lima), 20(2), e1208. https://doi.org/10.24265/horizmed.2020.v20n2.11

Rodríguez Aramayo, R. (2020). Reflexiones desde la filosofia: lo que COVID-19 puede enseñarnos.

Sanabria, J. R. (1987). Filosofía del hombre, México, Porrúa.

Serrano, P. G. (2020). Los retos ambientales ante la "nueva normalidad". IndustriAmbiente: gestión medioambiental y energética, (29), 60-62.

Tolentino de Mendonça, J. (2020). Cuarentena y Pascua. Vida Religiosa, 129(4), 29. Recuperado de https: / vidareligiosa.es/wp-content/uploads/2020/04/VR-mes-deabril.pdf 
UNESCO (2020). Reunión Global sobre la Educación 2020. Recuperado el 15 de diciembre de 2020 de https://es.unesco.org/sites/default/files/gem2020-extraordinary-session-concept-notees.pdf

Wilson, J. (1983), La vida, una pregunta y una respuesta, 2a. ed., Madrid, Pauli.

Yepes Stork, R. y Aranguren Echevarría, J. (2003). Fundamentos de Antropología, Pamplona, Eunsa. 